\title{
Anti-apartheid protestors safe?
}

SIR-Masters, Caithness and Rayner (Nature 320, 480; 1986) have proposed that there be a political-philosophical test on academics from South African institutions who wish to publish in international journals or to be admitted to conferences overseas. Their letter is a cri de couer reflecting the anguish, uncertainty and frustration of many scientists in South Africa who strongly oppose apartheid and look forward to a non-racial, democratic future, but whose dedication to the advancement of science and the freedom of movement of scientists now finds itself challenged by a growing tendency of countries and communities of scholars to exclude investigators resident in South Africa (as exemplified by the Southampton archaeology congress affair).

The acceptability of the proposal that a political test be applied before a scientist from a South African institution is admitted to an international congress is a subject for debate. Suffice it to say that the proposal is plainly at variance with policies on admission to international congresses maintained by two of the leading umbrella organizations of learned unions, the International Council of Scientific Unions and the International Council for Philosophy and Humanistic Studies.

But two points in the letter of Masters et al. may be misleading. First they state that "most funding for research (in South Africa) stems directly from the government". This is not strictly correct. It stems indirectly from government; as in Great Britain and the United States, statutory granting bodies are interposed between government and applicants for finance. Masters $e t$ al. then raise the possibility that congress participants, after signing an anti-apartheid document, might be "deprived of the financial support that should reasonably be theirs". This could be taken as a hint that the source of funding (commonly, the Council for Scientific and Industrial Research (CSIR), Foundation for Research Development, Medical Research Council (MRC) or Human Sciences Research Council) might penalize a researcher who signed an antiapartheid declaration by refusing financial support.

I believe such a supposition is unjustified. All the evidence available to me from the past history, especially of the CSIR and MRC, the two bodies with which I have had most dealings over the years, would discount any likelihood that they would lend themselves to such an action.

Ever since Field Marshal J.C. Smuts set up the CSIR, under the presidentship of Professor (later Sir) Basil Schonland, some forty years ago, the CSIR has been, to my knowledge, impeccably impartial in its disbursement of grants. For instance, despite the well known stand of the Universities of Cape Town and the Witwatersrand against apartheid since 1948, scientists at these two universities consistently received most generous funding from the CSIR. Such grants went even to scholars who were outspoken public critics of apartheid. Similar comments apply to those at universities such as Natal and Rhodes.

The same policy has characterized the MRC since its inception in 1969 under Professor A.J. Brink. I know of no evidence of political discrimination, in decisions on research grants, against those whose philosophical convictions opposed those of the government of the day.

Hence, I feel there is no basis in past experience for the veiled inference of Masters et al. that the CSIR, the MRC, or any other South African funding body might discriminate in the future against scholars who have signed an antiapartheid document such as they have proposed.

Department of Anatomy,

Phillip V. ToBias

Witwatersrand University

Medical School,

Johannesburg, South Africa

\section{Problems of Africa}

SIR-Can Michael Spencer (Nature 322, $10 ; 1986)$ substantiate his statement that "Britain fostered tribal rivalries in colonial days by recognizing the Kabaka of Buganda as ruler" of Uganda? My experience of colonial Uganda and Kenya was that the colonial administrators fostered tribal identity and development rather than trying to form a unitary state. The Kabaka was recognized as head of state of the country of Uganda (rather than of the Baganda and the country of Buganda) only on independence. In colonial times, he was head of one of the four provinces of Uganda - Buganda, Western (including the kingdoms of Bunyoro, Toro and Ankole), Northern and Eastern. As to Museveni's popularity, it is not as widely shared as one might wish, with half the population from the other tribal groupings.

Whether Britain has squandered its oil wealth is surely not relevant to whether Nigeria has done so. Alberta has not, and Nigeria might have taken Alberta as a sound model, but Alberta is also in economic trouble. Nevertheless, the fact that Nigeria has not conserved its oil wealth or used it as development capital has contributed to its present ecomomic woes.

Tanzania's falling income is due not only to falling prices of tea, coffee, sisal and other commodities but also to its systematic inability to maintain these agricultural industries. None of these commodities is easily available in Tanzania (as of March
1986) and even pepper and cloves are unobtainable in Arusha and other centres. Tanzania's economic woes are confirmed by its mismanagement of its foreign exchange, its insistence on an artificial and unrealistic exchange rate for its shillings at about 16 to the US dollar, when one shilling is really worth about two cents. The free market has caused part of the problem, but inability to allow for free market fluctuations, to keep the commodities being produced, to offer fair returns to the growers and to get the commodities to markets are basic to Tanzania's problem. In other words, it is a managerial problem.

As for the International Fund for Agricultural Development, that will succeed only if the population explosion in Africa is restrained, otherwise water and food will remain limiting and famine and disease will reduce many populations.

C.S. Churcher Ramsay Wright Zoological Laboratories, University of Toronto,

Toronto MSS 1A1,

Ontario, Canada

\section{Art of the "possible"}

SIR-In "What to believe about miracles" (Nature 322, 321; 1986), R.J. Berry starts off on the wrong foot. His conception of a law of nature, and hence of a miraculous overriding of such a law, is far too weak. For if such laws were, as he maintains, "only generalizations of our experience", then a miracle, as a counter-example to such a brute fact generalization, would be at most merely improbable. It is only and precisely because laws of nature assert much more than this that the occurrence of a genuine miracle would be evidence of divine intervention, an overriding of the natural order by a supernatural power.

Berry and his friends are, of course, absolutely right in their insistence that the occurrence of miracles is, in this understanding, possible. Or, rather, it is possible so long as "possible" is taken to mean conceivable or logically possible. What it is not is physically or naturally possible. For anything inconsistent with a true law of nature must be, by definition, impossible, in this understanding of impossible.

When Hume's once notorious argument is so amended as to admit this familiar kind of impossibility - something which Hume himself, like Berry, failed to recognize - it becomes a formidable demonstration: not of the inconceivability of the miraculous but of the extreme difficulty, to put it no stronger, of knowing, upon purely historical evidence, that any miracles have actually occurred. (I have myself attempted to supply such amendment: see my Hume: Philosopher of Moral Science; Blackwell, Oxford, 1986.)

26 Alexandra Road, ANTHONY FLEW

Reading, Berkshire RG1 5PD, UK 